\title{
Quetiapine versus Clozapine in Treating Psychiatric Patients with Severe COVID-19: A Netosis-Based Opinion
}

\author{
Mohsen Khosravi ${ }^{1 \star}$
}

${ }^{1}$ Department of Psychiatry and Clinical Psychology, Zahedan University of Medical Sciences, Zahedan, IRAN *Corresponding Author: dr_khosravi2016@yahoo.com

Citation: Khosravi M. Quetiapine versus Clozapine in Treating Psychiatric Patients with Severe COVID-19: A Netosis-Based Opinion. Electron J Gen Med. 2021;18(5):em301. https://doi.org/10.29333/ejgm/11010

\section{Dear Editor,}

The 2019 coronavirus disease (COVID-19), caused by the severe acute respiratory syndrome coronavirus 2 (SARS-CoV2), has led to millions of confirmed cases and deaths worldwide since it became a pandemic in May 2020. Like other viral respiratory pathogens, the SARS-CoV-2 may be associated with mild to severe clinical symptoms. In severe COVID-19 patients, developed acute respiratory distress syndrome (ARDS) can lead to respiratory failure and death by causing severe acute lung injury [1]. Recent evidence has suggested that the increased neutrophil represents the severity of respiratory symptoms and a poor prognosis among COVID-19 patients [2]. Among neutrophils' well-known effector mechanisms, neutrophil-derived extracellular traps (NETs) appear to be one of the most important in COVID-19 infection [3]. NETs are weblike structures of extracellular fibers composed of doublestranded DNA, histones, myeloperoxidase (MPO), and proteinase-3. The process of NETs formation (or NETosis) is initiated with neutrophil activation via pattern recognition receptors or chemokines and continues with ROS production and calcium mobilization, activating the protein arginine deiminase-4 (PAD-4) [3,4]. Although NETs were initially reported as neutrophil microbicidal mechanisms, additional evidence suggested that NETs have double-edged-sword activities [3]. In this regard, recent studies have shown that during clinical and experimental sepsis, the concentration of NETs increases in the bloodstream, which is positively correlated with sepsis severity and biomarkers of vital organ injuries. In addition, it has been demonstrated that inhibiting NETosis using recombinant human DNase (rhDNase) or PAD-4 inhibitors can significantly reduce organ damage, particularly in the lungs, and increase the survival rate of severe septic mice [5-9]. Given the well-known similarities between key factors involved in the pathophysiology of sepsis and COVID-19 (e.g., cytokine overproduction, micro-thrombosis, and ARDS), it can be hypothesized that lung tissue damage in COVID-19 patients may be due to SARS-CoV-2-triggered NETosis [2,3]. In support of this hypothesis, recent researches have shown an increase in the concentration of NETs in the plasma and lungs of COVID-19 patients [10-12]. In detail, SARS-CoV-2 can induce apoptosis of lung epithelial cells by directly stimulating NETosis in healthy neutrophils in mechanisms dependent on the angiotensinconverting enzyme (ACE2)-serine protease axis, virus replication, and PAD-4 signaling. These findings indicate the significant role of NETosis in destroying lung epithelial cells as a part of the pathophysiology of severe COVID-19 infection. Hence, the use of NETosis stimulants can exacerbate pulmonary epithelial cell damage among COVID-19 patients $[2,3]$. Recently, the effect of two common second-generation antipsychotic drugs, namely quetiapine and clozapine, has been investigated on innate immune cells $[4,13]$. A new study on the in vitro impact of unmetabolized quetiapine on innate immune cells has shown that unmetabolized quetiapine increases formation of NETs via activated neutrophils. These results confirm the impact of quetiapine on neutrophil function, which may aggravate NETs formation and pulmonary epithelial cell damage during severe SARS-CoV-2 infection [13]. In contrast, researchers have not found any similar action in neutrophils exposed to antipsychotic clozapine [4]. Although these findings are derived from the preliminary in vitro studies, psychiatrists and other mental health professionals should be more careful about initiating or continuing quetiapine treatment in psychiatric patients with severe COVID-19 infection until the completion of information. However, regardless of other challenges of using clozapine in the COVID19 era (such as the overlap between clozapine-induced side effects and COVID-19 symptoms and sequelae, and practical difficulties in regular laboratory monitoring), its continuation appears to be safe in psychiatric patients with severe SARSCoV-2 infection [14-17].

Funding: No funding source is reported for this study.

Declaration of interest: No conflict of interest is declared by author.

\section{REFERENCES}

1. Lai CC, Shih TP, Ko WC, Tang HJ, Hsueh PR. Severe acute respiratory syndrome coronavirus 2 (SARS-CoV-2) and coronavirus disease-2019 (COVID-19): The epidemic and the challenges. Int J Antimicrob Agents. 2020;55:105924. https://doi.org/10.1016/j.ijantimicag.2020.105924 PMID: 32081636 PMCID:PMC7127800

2. Chiang CC, Korinek M, Cheng WJ, Hwang TL. Targeting neutrophils to treat acute respiratory distress syndrome in Coronavirus disease. Front Pharmacol. 2020;11:572009. https://doi.org/10.3389/fphar.2020.572009 PMID: 33162887 PMCID:PMC7583590 
3. Veras FP, Pontelli MC, Silva CM, Toller-Kawahisa JE, de Lima M, Nascimento DC, et al. SARS-CoV-2-triggered neutrophil extracellular traps mediate COVID-19 pathology.J Exp Med. 2020;217:e20201129. https://doi.org/ 10.1084/jem.20201129 PMID:32926098 PMCID:PMC7488868

4. Irizarry-Caro JA, Carmona-Rivera C, Schwartz DM, Khaznadar SS, Kaplan MJ, Grayson PC. Drugs Implicated in Systemic Autoimmunity Modulate Neutrophil Extracellular Trap Formation. Arthritis Rheumatol. 2018;70:468-74. https://doi.org/10.1002/art.40372 PMID:29121457 PMCID: PMC5826843

5. Colón DF, Wanderley CW, Franchin M, Silva CM, Hiroki CH, Castanheira FV, et al. Neutrophil extracellular traps (NETs) exacerbate severity of infant sepsis. Crit Care. 2019;23:113. https://doi.org/10.1186/s13054-019-2407-8 PMID:30961634 PMCID: PMC6454713

6. Czaikoski PG, Mota JM, Nascimento DC, Sônego F, Castanheira FV, Melo PH, et al. Neutrophil extracellular traps induce organ damage during experimental and clinical sepsis. PLoS One. 2016;11:e0148142. https://doi. org/10.1371/journal.pone.0148142 PMID:26849138 PMCID: PMC4743982

7. Kambas K, Mitroulis I, Apostolidou E, Girod A, Chrysanthopoulou A, Pneumatikos I, et al. Autophagy mediates the delivery of thrombogenic tissue factor to neutrophil extracellular traps in human sepsis. PLoS One. 2012;7:e45427. https://doi.org/10.1371/journal.pone.0045 427 PMID: 23029002 PMCID: PMC3446899

8. Martinod K, Fuchs TA, Zitomersky NL, Wong SL, Demers M, et al. PAD4-deficiency does not affect bacteremia in polymicrobial sepsis and ameliorates endotoxemic shock. Blood. 2015;125:1948-56. https://doi.org/10.1182/blood2014-07-587709 PMID:25624317 PMCID: PMC4366625

9. Clark SR, Ma AC, Tavener SA, McDonald B, Goodarzi Z, Kelly MM, et al. Platelet TLR4 activates neutrophil extracellular traps to ensnare bacteria in septic blood. Nat Med. 2007;13:463-9. https://doi.org/10.1038/nm1565 PMID: 17384648

10. Middleton EA, He XY, Denorme F, Campbell RA, Ng D, Salvatore SP, et al. Neutrophil extracellular traps contribute to immunothrombosis in COVID-19 acute respiratory distress syndrome. Blood. 2020;136:1169-79. https://doi.org/10.1182/blood.2020007008 PMID: 32597954 PMCID:PMC7472714
11. Zuo Y, Zuo M, Yalavarthi S, Gockman K, Madison JA, Shi H, et al. Neutrophil extracellular traps and thrombosis in COVID-19. Neutrophil extracellular traps and thrombosis in COVID-19. J Thromb Thrombolysis. 2021;51:446-53. https://doi.org/10.1007/s11239-020-02324-z PMID:33151461 PMCID:PMC7642240

12. Skendros P, Mitsios A, Chrysanthopoulou A, Mastellos DC, Metallidis S, Rafailidis $P$, et al. Complement and tissue factor-enriched neutrophil extracellular traps are key drivers in COVID-19 immunothrombosis. J Clin Invest. 2020;130:6151-6157. https://doi.org/10.1172/JCI141374 PMID:32759504 PMCID:PMC7598040

13. Turra BO, Barbisan F, Azzolin VF, Teixeira CF, Flores T, Braun LE, et al. Unmetabolized quetiapine exerts an in vitro effect on innate immune cells by modulating inflammatory response and neutrophil extracellular trap formation. Biomed Pharmacother. 2020;131:110497. https://doi.org/ 10.1016/j.biopha.2020.110497 PMID:33152899

14. Gee S, Gaughran F, MacCabe J, Shergill S, Whiskey E, Taylor D. Management of clozapine treatment during the COVID19 pandemic. Ther Adv Psychopharmacol. 2020;10:2045125320928167. https://doi.org/10.1177/20451 25320928167 PMID:32542111 PMCID:PMC7256815

15. Govind R, de Freitas DF, Pritchard M, Hayes RD, MacCabe $\mathrm{JH}$. Clozapine treatment and risk of COVID-19 infection: retrospective cohort study. $\mathrm{Br} J$ Psychiatry. 2020;1-7. https://doi.org/10.1192/bjp.2020.151 PMID:32713374 PMCID:PMC7417985

16. Khosravi M. Ursodeoxycholic Acid in Patients with Treatment-Resistant Schizophrenia Suffering From Coronavirus Disease 2019: A Hypothesis Letter. Front Psychiatry. 2021;12:657316. https://doi.org/10.3389/ fpsyt.2021.657316 PMID:33935842 PMCID:PMC8079749

17. Khosravi M. COVID-19 Pandemic: What are the Risks and Challenges for Schizophrenia?. Clin Schizophr Relat Psychoses. 2020;14:110320. https://doi.org/10.3371/CSRP. KM.110320 